\author{
Lizandro B. de Mello \\ Paulo V. P. Marcondes \\ marcondes@demec.ufpr.br \\ Departamento de Engenharia Mecânica \\ Universidade Federal do Paraná \\ Jardim das Américas - Centro Politécnico \\ Caixa Postal 19011 \\ 81531-990 Curitiba, PR, Brazil
}

\section{Punching and Broaching Combos - a Newstamping Tool}

The crescent searches for the reduction in time production are a factor that stimulates the improvement of the existent manufacturing techniques (Von Steeg 2002 and Waurzyniak 2002). Nowadays, the new researched processes should make possible the fabrication of pieces in a smaller time with a better use of the material resources and equipments (Klein 2002). The present work has for objective to show the viability of a combined tool that makes possible to perform a punching followed by a broaching in only one operation. This combo allies the advantages of the forming processes production and machining in only one process for heavy duty jobs on thick metal sheets. In this work were tested different configurations of combined punches. The objective was to analyze which are the main parameters that can have influence on the useful life of the tool in this new process, i.e., diameter of the punches and geometric form of the teeth for broaching. The precision overall depth of the holes, the roughness and the level of metal chip generation were measured. The analysis of the obtained data showed that the process is viable once were obtained holes with superior quality to the conventional stamping processes.

Keywords: Hole making, thick metal sheets, punching, broaching

\section{Introduction}

This work is a practical study that tries to evaluate the viability of a combined tool of punching and broaching. The objective was to obtain cylindrical holes on thick sheets with good dimensional quality and surface finish. In this new process is possible to ally the job shop flexibility of the stamping and the good capabilities of the machining processes getting a larger speed in the obtaining of holes in heavy duty jobs with fine tolerances.

The main motivation for the development of this new tool is the elimination of a problem that happens during the punching of thick sheets, thickness bigger than $6 \mathrm{~mm}$ (Luo 1997, Faura et al. 1998 and Schaeffer 1999). When sheets of that thickness are punched happens the "blow-out" effect, in other words, during withdrawal of the punch the hole becomes larger than the wanted diameter becoming a conical hole (Altan et al. 1999 and Mello 2001). This can be observed in the Fig. 1, where we have the sheet slug - stock thickness of $8 \mathrm{~mm}$. Analyzing the scrap, is clearly observed a difference in the diameters. The smaller diameter corresponds to the initial area of contact of the punch with the sheet and the larger diameter is the area of withdrawal of the punch.

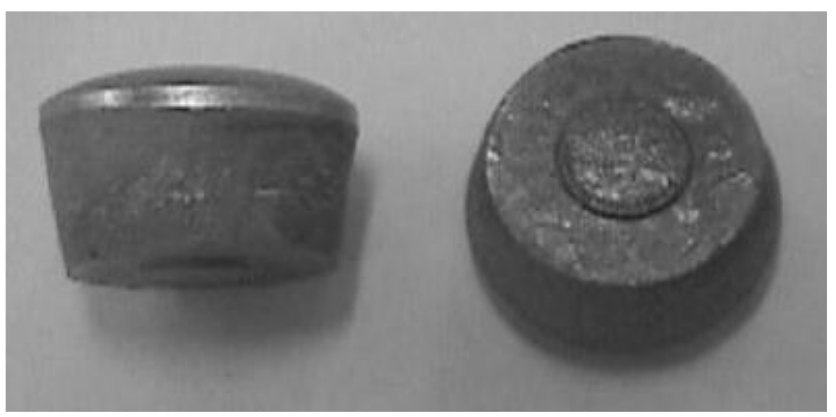

Figure 1. An $8,0 \mathrm{~mm}$ sheet slug evidencing the material " blow-out".

The blow-out effect became worse with the elevation of the hardness of the work material and mainly with the increase of the stock thickness (Society of Manufacturing Engineering, 1990). The traditional solution for elimination of that problem would be to submit the sheet to a conventional process of broaching or

Paper accepted September, 2005. Technical Editor: Atila P. Silva Freire. enlargement. However, these operations demand additional time (Ferraresi 1974 and Stemmer 1992). Furthermore, it also involves an application of other machines and tools turning the process slower and more expensive.

In this work were analyzed several items in order to identify the main variables and the influences on the process, i.e., geometry of the tool, number of teeth for broaching, useful life of the tools, precision overall depth of the holes, surface finish and amount and form of the generated metal chips.

\section{Experimental Procedure}

The proposed test for verification of the viability of a new punching and broaching combo process was to build a stamping tool composed basically by punch and die. The punch was endowed with broaching teeth, Figure 2. It was varied the punch diameters, number of teeth and it's geometry. Afterwards, it was carried out the punching operation with broaching in a thick metal sheet varying the punches and monitoring the parameters of the process. After the operations, the measurements of the relevant parameters, such as: roughness and the conical form of the punched holes were made in order to analyze the process viability.

In resume, during the tests it was evaluated the following process characteristics: better geometric configuration of the tool, in other words, simple teeth or simple teeth cutting with gullet area (place for chip disposal), better configuration of the number of teeth, influence of the diameter of the hole and the life of the tool.

In order to do the tests it was build punches for three different holes diameter $(\varnothing 10,17$ and $24 \mathrm{~mm})$. For each diameter four punch types (geometry 1 to 4 ) were built varying, in this case, the geometry and the number of teeth. It was built two punches for each geometry performing a total of 24 punches, according to the Table 1.

Table 1. Punch types.

\begin{tabular}{|c|c|c|c|c|}
\hline Diameter & \multicolumn{4}{|c|}{ Geometry } \\
\hline $10 \mathrm{~mm}$ & 1 & 2 & 3 & 4 \\
\hline $17 \mathrm{~mm}$ & 1 & 2 & 3 & 4 \\
\hline $24 \mathrm{~mm}$ & 1 & 2 & 3 & 4 \\
\hline
\end{tabular}

The Figure 2 illustrates the dimensions of the punch of $\varnothing 10 \mathrm{~mm}$ with geometries $1,2,3$ and 4 . The punches of $\varnothing 17 \mathrm{~mm}$ and $\varnothing 24 \mathrm{~mm}$ follow the same geometric characteristics 1,2, 3 and 4 presented for the punch of $\varnothing 10 \mathrm{~mm}$, altering only their respective dimension. 
The parameters involved in the tests were divided in: variables and constants. The parameters maintained constants were: material of the punch and dies, thickness and type of the sheet metal, lubrication, temperature and the load and speed parameters of the utilized mechanical press. The studied parameters along the experiment were: number of cutting teeth of the broach, step of the broach (distance between teeth), presence of the gullet area for metal chips and the diameters of the punch. The analyzed parameters were: precision overall depth of the holes, the hole final roughness (surface finish) and the punch wear (just visual evaluation).
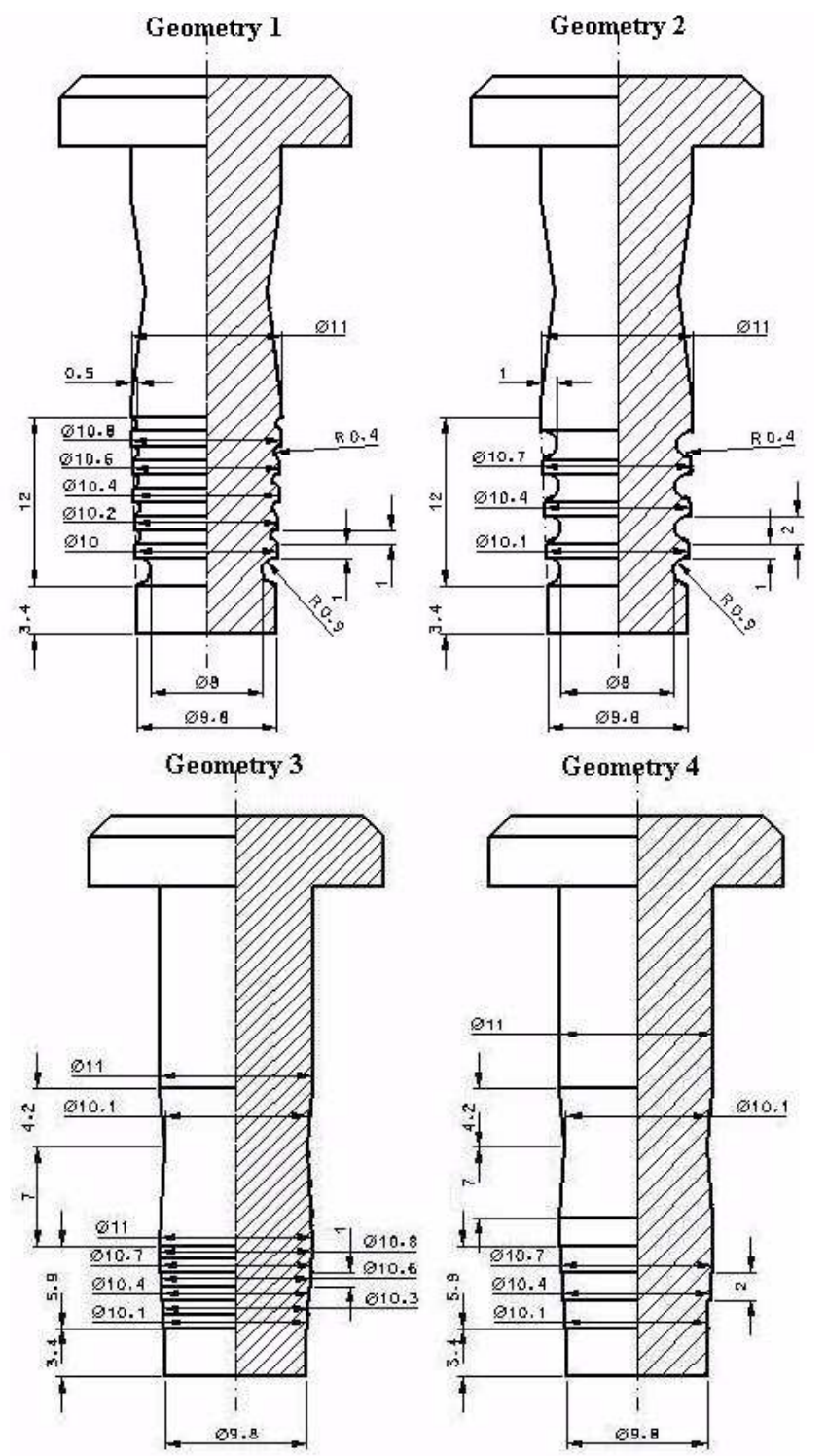

Figure 2. Geometries and dimensions of the punch of $\varnothing 10 \mathrm{~mm}$.

The punch and dies were manufactured of VC-131 steel (temper hardened and annealed), Figure 3. All the punches were produced from the same raw material and heated treated together. The three complete set of tools were composed of die and punch, inferior base, drawer, punch carrier, shock plate and superior base. These tools were fixed at a base, $40 \mathrm{~mm}$ of thickness, with two columns of diameter $35 \mathrm{~mm}$ with the objective of increasing the stability of the process and the quality of the alignment of the die with the punch.

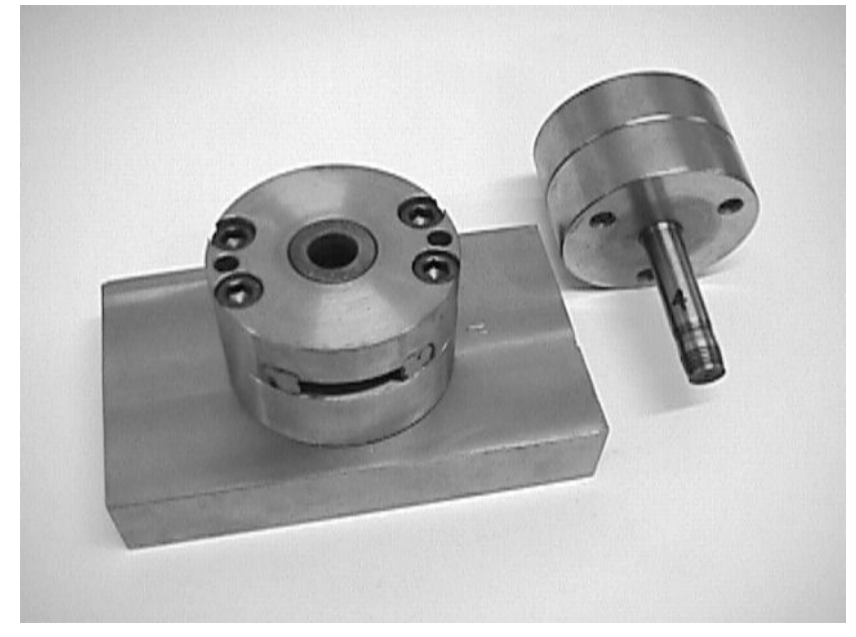

Figure 3. Tool set for holes of $\varnothing 10 \mathrm{~mm}$.

The sheets used in the tests have the following specification: NBR 6656 LNE 38 strips, $8,0 \mathrm{~mm}$ thick. The strips were obtained of sheets of a same lot (same lamination race) to avoid interferences due to the material quality variations. The proof peaces used were: 8 strips of width $20 \mathrm{~mm}$ and length $1500 \mathrm{~mm}, 8$ strips of width $34 \mathrm{~mm}$ and length $1500 \mathrm{~mm}$ and 12 strips of width $50 \mathrm{~mm}$ and length $1500 \mathrm{~mm}$, totaling approximately $100 \mathrm{Kg}$ of raw material. The used equipments were: Mechanical press with capacity of 100 tons (La Mundial - type C), a digital camera Sony MV7, a Mitutoyo digital equipment with resolution of $0,01 \mathrm{~mm}$ and a Hommelwerke contact roughness equipment TKE 100-739, r: $5 \mu \mathrm{m}$ and $\mathrm{R}: 10 \mathrm{~mm}$.

The experiment went through the following procedure: preparation of the strips with the widths and lengths established previously, always the same mechanical press, to punch 100 holes in sequence with each one of the two series of punches. All the punches were lubricated with the same oil (Castrol Ratak).

\section{Results and Discussion}

With the punch of geometry $2, \varnothing 10 \mathrm{~mm}$, in the better case 15 consecutive holes were stamped and were observed a head breakage. Also for the better case with the punch of geometry $4, \varnothing$ $10 \mathrm{~mm}, 84$ consecutive holes were stamped before the punch head breakage occurs. The punch head breakage was attributed to the high extraction resistance caused by the high level of metal chips generated in these broaching cases. With all the other punches 100 consecutive holes were executed. For the punches of geometry 1 and $3, \varnothing 10 \mathrm{~mm}$, a temperature increase was observed during work, mainly when the interval between holes was very small. Moreover, it was verified due to the fast filling of the broach gullets with the metal chips a tool pickup effect (chip adhering to broach). However, the punch of geometry 3 presented a reduction in the level of generated metal chips and a better superficial finish of the performed holes. It was also observed an accentuated elevation in the extraction force when compared with the operation of conventional punching.

By the other hand, for the punch of geometry $1, \varnothing 17 \mathrm{~mm}$, a great amount of metal chips was obtained, i.e., quite superior that observed for the punch of geometry $1(\varnothing 10 \mathrm{~mm})$. In some moments the excess of metal chips locked the strip material displacement in the drawer of the tool. The heating was also quite accentuated and, also, was observed the tool pickup effect. The broach gullets were completely filled out on the starting first punched holes. The punch of geometry $2, \varnothing 17 \mathrm{~mm}$, presented identical results. The punches of geometry 3 and $4, \varnothing 17 \mathrm{~mm}$, showed a good reduction in the amount

\section{J. of the Braz. Soc. of Mech. Sci. \& Eng.


of generated metal chips and the temperature was maintained at lower levels.

Finally, the punches of $\varnothing 24 \mathrm{~mm}$ showed a behavior similar to the punches of $\varnothing 10 \mathrm{~mm}$, but it was observed in some cases a breakage of the some broach teeth, probably in function of the increase of the volume of removed material.

In all the cases a superior superficial finish was observed if compared to the conventional finish obtained with the operation of conventional punching, Figure 4.

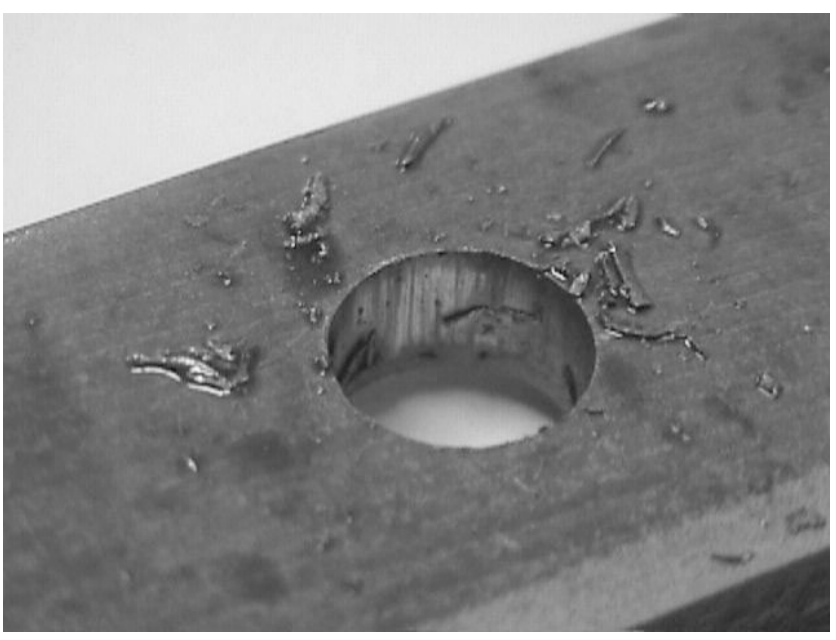

Figure 4. Surface finish of the punched and broached hole.

In order to analyze the precision overall depth of the punched parts the diameters of three holes were measured along the 100 stampings, one in the first 10 holes $\left(1^{\text {st }}\right.$ hole in the Table 2$)$, the second one located between the holes number 40 and $60\left(2^{\text {nd }}\right.$ hole in the Table 2), and the last one located among the holes 90 and 100 ( $3^{\text {rd }}$ hole in the table 2$)$. In this case, we have an exception for the punch of geometry 4 , diameter $10 \mathrm{~mm}$, which only stamped 84 holes and the punch of geometry 2 (also diameter of $10 \mathrm{~mm}$ ) that broke in the first 15 holes. The measurements always were performed between the thickness of 4 and $6 \mathrm{~mm}$ (exit area of the punch). The roughness was measured by moving the sensor of the roughness equipment in the same direction of displacement of the punch during the broaching process.

It was also analyzed the generation of metal chips by the broaching process (machined chips). The evaluation was visual, being indicated with an arrow down $(\downarrow)$ for the punches that produced metal chips in smaller level and dimensions and with the arrow upward $(\uparrow)$ for that ones that produced larger metal chips and with larger intensity.

The life of the tool was evaluated according with the tendency of the material to fill the broaching bags (that will reduce the broaching life), breaks of teeth and the decrease of the diameter along the 100 stamped holes. In this case, being larger tool life for the arrow upward ( $\uparrow$ ) and smaller tool life for the arrow down $(\downarrow)$. An overview of the obtained results is presented in the Table 2.

The precision overall depth of the holes was calculated as being the difference of the diameter of the hole in the entrance of the punch subtracted of the value of the diameter of the hole in the exit area of the punch, Table- 3 . It was analyzed the $1^{\text {st }}$ and the $3^{\text {rd }}$ holes of Table-2.

The precision overall depth of the holes was calculated as being the difference of the diameter of the hole in the entrance of the punch subtracted of the value of the diameter of the hole in the exit area of the punch, Table- 3 . It was analyzed the $1^{\text {st }}$ and the $3^{\text {rd }}$ holes of Table-2.

In general, the obtained results showed that the punches of the types 3 and 4 promoted a superior hole qualities compared with that holes obtained for the punch types 1 and 2. Punches type 3 and 4 gave a superior tool life and a quite inferior level of metal chips. The punches with the configuration number 3 were the ones that showed the more stable process characteristics during the three studied diameters, while the others presented problems related to the life of the punch or to the level of burrs and/or breakage. Moreover, the configuration number 3 was the one that presented the best performance during work. In Table 4 is given a summary of the observed behavior of the punches and the mainly general observations obtained during the experiments.

Table 2. General obtained results.

\begin{tabular}{|c|c|c|c|c|c|c|c|c|}
\hline \multirow{2}{*}{$\begin{array}{l}\text { Diameter } \\
(\mathbf{m m})\end{array}$} & \multirow[t]{2}{*}{ Type } & \multicolumn{3}{|c|}{$\begin{array}{c}\text { Diameter of the punched } \\
\text { holes (mm) }\end{array}$} & \multirow{2}{*}{$\begin{array}{l}\text { Roughness in the beginning } \\
\qquad \operatorname{Ra}(\text { medium) }\end{array}$} & \multirow{2}{*}{$\begin{array}{l}\text { Roughness in the end } \\
\text { Ra(medium) }\end{array}$} & \multirow[t]{2}{*}{ Metal Chips } & \multirow[t]{2}{*}{ Life } \\
\hline & & $1^{\text {st }}$ hole & $2^{\text {nd }}$ hole & $3^{\text {rd }}$ hole & & & & \\
\hline \multirow{4}{*}{10} & 1 & 10,90 & 10,90 & 10,90 & - & - & $\uparrow$ & $\uparrow$ \\
\hline & 2 & - & - & - & - & - & $\uparrow$ & $\downarrow$ \\
\hline & 3 & 10,97 & 11,03 & 11,04 & - & - & $\downarrow$ & $\uparrow$ \\
\hline & 4 & 10,95 & 10,96 & - & - & - & $\downarrow$ & $\downarrow$ \\
\hline \multirow{4}{*}{17} & 1 & 16,47 & 16,50 & 16,50 & 1,27 & 2,38 & $\uparrow$ & $\uparrow$ \\
\hline & 2 & 16,43 & 16,38 & 16,37 & 0,95 & 1,40 & $\uparrow$ & $\uparrow$ \\
\hline & 3 & 16,48 & 16,42 & 16,47 & 0,20 & 1,20 & $\downarrow$ & $\uparrow$ \\
\hline & 4 & 16,51 & 16,45 & 16,48 & - & - & $\downarrow$ & $\downarrow$ \\
\hline \multirow{4}{*}{24} & 1 & 24,38 & 24,35 & 24,37 & 0,33 & 0,85 & $\uparrow$ & $\uparrow$ \\
\hline & 2 & 24,35 & 24,36 & 24,34 & 0,75 & 0,80 & $\uparrow$ & $\downarrow$ \\
\hline & 3 & 24,35 & 24,40 & 24,41 & 0,30 & 0,15 & $\downarrow$ & $\uparrow$ \\
\hline & 4 & 24,41 & 24,40 & 24,40 & 0,40 & 0,60 & $\downarrow$ & $\uparrow$ \\
\hline
\end{tabular}


Table 3. Precision overall depth of the punched and broached holes.

\begin{tabular}{|c|c|c|c|}
\hline $\begin{array}{c}\text { Diameter } \\
(\mathbf{m m})\end{array}$ & Type & $\begin{array}{c}\text { Precision overall } \\
\text { depth of the holes } \\
\text { 1st hole }\end{array}$ & $\begin{array}{c}\text { Precision overall } \\
\text { depth of the holes } \\
\text { 3rd hole }\end{array}$ \\
\hline \multirow{5}{*}{10} & 1 & 0,060 & 0,010 \\
\cline { 2 - 4 } & 2 & 0,020 & 0,030 \\
\hline \multirow{5}{*}{17} & 3 & 0,020 & 0,010 \\
\hline & 4 & 0,025 & 0,020 \\
\hline \multirow{5}{*}{24} & 2 & 0,020 & 0,056 \\
\hline & 3 & 0,050 & 0,080 \\
\hline & 4 & 0,120 & 0,095 \\
\hline & 2 & 0,067 & 0,033 \\
\hline & 2 & 0,030 & 0,025 \\
\cline { 2 - 4 } & 3 & 0,020 & 0,038 \\
\hline & 4 & 0,035 & 0,032 \\
\hline
\end{tabular}

Table 4. Summary of the observed characteristics of the experiments.

\begin{tabular}{|c|c|c|c|c|}
\hline $\begin{array}{l}\text { Punch } \\
\text { Ø 10mm }\end{array}$ & Geometry & $\begin{array}{c}\mathbf{N}^{0} \text { of stamped } \\
\text { holes }\end{array}$ & Behavior & General Observations \\
\hline 1 & 5 teeth + gullet area & 100 & $\begin{array}{l}\text { - High resistance for the extraction. } \\
\text { - After the first holes there was a gullet } \\
\text { area filling with chips. }\end{array}$ & $\begin{array}{l}\text { Breakage on the punch head attributed to } \\
\text { the high extraction force and small } \\
\text { resistance in traverse section. }\end{array}$ \\
\hline 2 & 3 teeth + gullet area & $15 *$ & $\begin{array}{l}\text { - High resistance for the extraction. } \\
\text { - Larger metal chips. } \\
\text { - After the first holes there was a gullet } \\
\text { area filling with chips. }\end{array}$ & $\begin{array}{l}\text { Breakage on the head. High extraction } \\
\text { force and the small resistance in traverse } \\
\text { section. } \\
\text { Breakage on the area of the teeth. } \\
\text { In both cases the punch was arrested in } \\
\text { the strip. }\end{array}$ \\
\hline 3 & 7 teeth, without gullet area & 100 & $\begin{array}{l}\text { - For twice the punch was arrested in } \\
\text { the guide. }\end{array}$ & Normal \\
\hline 4 & 4 teeth, without gullet area & $\begin{array}{l}84 * \\
76 * *\end{array}$ & $\begin{array}{l}\text { - The punch was arrested in the strip for } \\
\text { both cases. }\end{array}$ & Break of the head of the two punches. \\
\hline
\end{tabular}

\begin{tabular}{|c|c|c|c|c|}
\hline \multicolumn{5}{|c|}{ * 1st Punch $\quad * * 2$ nd Punch } \\
\hline $\begin{array}{c}\text { Punch } \\
\varnothing 17 \mathrm{~mm}\end{array}$ & Geometry & $\begin{array}{c}\mathbf{N}^{0} \text { of stamped } \\
\text { holes }\end{array}$ & Behavior & General Observations \\
\hline 1 & 5 teeth + gullet area & 100 & $\begin{array}{l}\text { - Increase of the amount of chips. } \\
\text { - The chips locked the strip's } \\
\text { displacement. } \\
\text { - Fast gullet area filling with chips. }\end{array}$ & Breakage on the head. \\
\hline 2 & 3 teeth + gullet area & 100 & - Same behavior of the punch $1(\varnothing 17)$ & Normal \\
\hline 3 & 7 teeth, without gullet area & 100 & $\begin{array}{l}\text { - The chip level was smaller than with } \\
\text { the punch } 1(\varnothing 17) \text {. } \\
\text { - The tool pickup effect was smaller } \\
\text { because of the absence of the gullet } \\
\text { area. }\end{array}$ & Normal \\
\hline 4 & 4 teeth, without gullet area & 100 & $\begin{array}{l}\text { - Smaller level of chips. Lightly smaller } \\
\text { than with the punch } 3(\varnothing 17) \text {, however } \\
\text { with higher dimensions. }\end{array}$ & Breakage of the first tooth. \\
\hline
\end{tabular}

\begin{tabular}{|c|c|c|c|c|}
\hline $\begin{array}{l}\text { Punch } \\
\text { Ø 24mm }\end{array}$ & Geometry & $\begin{array}{c}\mathrm{N}^{0} \text { of stamped } \\
\text { holes }\end{array}$ & Behavior & General Observations \\
\hline 1 & 5 teeth + gullet area & 100 & $\begin{array}{l}\text { - Basically, it was observed the same } \\
\text { characteristics of the punch } 1(\varnothing 10 \\
\mathrm{mm}) .\end{array}$ & Tool pickup effect. \\
\hline 2 & 3 teeth + gullet area & 100 & $\begin{array}{l}\text { - A high level of chips was observed. } \\
\text { - High level of tool pickup effect. }\end{array}$ & $\begin{array}{l}\text { Breakage of the last tooth. The stamping } \\
\text { forces are significantly superiors for the } \\
\text { diameter of } 24 \mathrm{~mm} \text {. }\end{array}$ \\
\hline 3 & 7 teeth, without gullet area & 100 & - Low level of chips. & Normal. \\
\hline 4 & 4 teeth, without gullet area & 100 & $\begin{array}{l}\text { - Basically the same results of the } \\
\text { punch } 3(\varnothing 24) .\end{array}$ & Breakage of the first tooth. \\
\hline
\end{tabular}

Finally, an important characteristic observed was that the punches for the studied dimensions should not have the gullet area (place for metal chips disposal - as the punches of the configuration 1 and 2). In this case, the gullet area cannot be very big otherwise it will cause the weakness of the central section of the punch. In the three studied situations the gullet area could not absorb all the generated amount of chips. A tool pickup effect can occurs very easily, too. In this work, also, for all geometries and dimensions

J. of the Braz. Soc. of Mech. Sci. \& Eng. Copyright @ 2006 by ABCM January-March 2006, Vol. XXVIII, No. 1 / 97 
studied the older formed chip was not displaced by the former chip adhered to broach tooth. Moreover, in the studied dimensions it was observed a quick metal chips filling of these cavities turning them inoperative. It was also observed that the process suffers strong heating deserving an intensive lubrication.

\section{Conclusions}

This study provided a good initial evaluation for the use of a combined tool of punching and broaching. The viability of the process was confirmed since was obtained a significant number of holes with superior superficial finish compared to that obtained with the conventional stamping process. A high dimensional precision was obtained too. Moreover, was still eliminated the conical deviation of the holes caused by the blow-out effect. In general the studied punches showed a good dimensional stability, in other words, they did not suffer enough wear in the teeth that could compromise the application of the tool regarding the useful life and/or tolerances.

Some aspects still deserve more project attention, as in the case of the form and the disposition of the broaching teeth, once high level of metal chips generation during broaching can damage the tools and to interrupt the process. The general process parameters as lubrication and temperature, also, deserve to be more carefully studied since a great dissipation of thermal energy was observed.

Traditionally, for the thick metal sheet the perforating process is an economical alternative of manufacture. With this new process we could provide a significant reduction in the costs and times of production with smaller material waste and maintaining the quality patterns demanded by the market.

\section{References}

Altan, T., Oh, Soo-Ik and Gegel, H. L., 1999, "Conformação Mecânica dos Metais - Fundamentos e Aplicações”, Editora EESC-USP, São Carlos SP.

Faura, F., García, A. and Estrems, M., 1998, "Finite element analysis of optimum clearance in the blanking process", Journal of Materials Processing Technology, 80-81, 121-125.

Ferraresi, D., 1974, "Usinagem dos Metais", $3^{\text {a }}$ Edição, ABM Associação Brasileira de Metais, São Paulo - SP.

Klein, A., 2002, "Do More During Punching”, www.sme.org/Forming\&Fabricating, 9/2002, 53-55

Luo, S. Y., 1997, "Studies on the wear conditions and the sheared edges in punching", Wear 208, 81-90, Elsevier Science.

Mello, L. B. de, 2001, "Ferramenta Combinada de Puncionamento e Brochamento", Monografia do Curso de Especialização em Engenharia de Materiais Metálicos, Departamento de Engenharia Mecânica, Universidade Federal do Paraná, Curitiba - PR.

Schaeffer, L., 1999, "Conformação Mecânica", Imprensa Livre Editora, Porto Alegre - RS

Society Of Manufacturing Engineers (SME), 1990, "Die Design

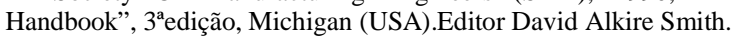

Stemmer, C. E., 1992, "Ferramentas de corte II : Brocas, alargadores, ferramentas de roscar, fresas, brochas, rebolos, abrasivos". Editora da UFSC. Florianópolis.

Von Steeg, M. B., 2002, "Laser/Punch Combos Provide Job Versatility", www.sme.org/Forming\&Fabricating, 11/2002, 45-50.

Waurzniak, P., 2002, "Holemaking with Precision", www.sme.org/manufacturingengineering, 11/2002, 51-56. 